\title{
PENYULUHAN HUKUM TERHADAP SIKAP SISWA ANTAR SUKU TERKAIT PENGAMALAN SILA KE-3 PANCASILA DI PESANTREN RUMAH QURAN UMAR BIN KHATTAB BOGOR
}

\author{
Rizka Amelia Azis ${ }^{1}$, Wasis Susetio ${ }^{2}$, Nurhayani $^{3}$, Elok Hikmawati ${ }^{4}$ \\ Fakultas Hukum, Universitas Esa Unggul, Jakarta \\ Jalan Arjuna Utara Nomor 9, Kebon Jeruk, Jakarta Barat - 11510 \\ rizka.amelia@esaunggul.ac.id
}

\begin{abstract}
Partners in this Community Service activity are santri at the Rumah Quran Umar bin Khattab Islamic Boarding School, whose address is Jl. Kp. Bojong Hilir No.12, Bojong, Kec. Kemamng, Bogor, West Java. This community service activity starts from April 2020 to August 2020 which begins with an audience, a meeting to discuss themes, signing of collaboration and implementing education / counseling. Pancasila can be used in every element of institutions, education, culture and organizational organizations in Indonesia, for example in Islamic boarding schools. Pesantren as the oldest education in Indonesia is growing rapidly and is big. Its development is not only textual, but also more up-to-date with the times, with the aim of preparing more advanced students or santri, not only experts in the field of religion, but also on governance, which are also encouraged by holding education in Islamic boarding schools. The lack of awareness of the students regarding the sense of national unity and integrity has led to the emergence of inter-ethnic groups there. For this reason, education and legal counseling are important to carry out so that ethnic differences between santri can still foster a sense of mutual cooperation between students and a sense of national unity. It is hoped that this counseling and education can provide useful information and input and add to the knowledge and insights of the students regarding character planting, especially related to the inculcation of the value of unity and responsibility in everyday life and in social life. The aim is so that the students can find out about the factors that cause things that destroy unity and what steps should be taken if things happen that can eliminate the sense of unity and oneness. The output that will be produced in this activity is a report on the results of community service along with P2M articles which will be published in the journal Abdimas Community Service. In this article, we will look for the steps in carrying out these activities, so that the method can be applied in other places with the same problem conditions.
\end{abstract}

Keywords: Indonesian Unity

\begin{abstract}
Abstrak
Mitra dalam kegiatan Pengabdian Kepada Masyarakat ini adalah santri di Pesantren Rumah Quran Umar bin Khattab yang beralamat di Jl. Kp. Bojong Hilir No.12, Bojong, Kec. Kemamng, Bogor, Jawa Barat. Kegiatan pengabdian masyarakat ini dimulai dari bulan April 2020 sampai dengan bulan Agustus 2020 yang diawali dengan audiensi, rapat pembahasan tema, penandatangan kerjasama dan pelaksanaan edukasi/penyuluhan. Pancasila dapat difungsikan dalam setiap elemen kelembagaan, pendidikan, kebudayaan, dan organisasiorganisasi di Indonesia, misalnya di pesantren. Pesantren sebagai pendidikan tertua di Indonesia sangat berkembang pesat dan besar. Perkembangannya pun tidak hanya pada tekstual, namun lebih mengikuti perkembangan zaman, dengan tujuan mempersiapkan siswa atau santri lebih maju, bukan hanya ahli di bidang agama, namun tentang kepemerintahan juga digalakkan dengan diadakan Pendidikan-pendidikan di Pesantren. Kurangnya kesadaran para santri terkait rasa persatuan dan kesatuan bangsa, menimbulkan terjadinya kelompokkelompok antarsuku disana. Untuk itu, edukasi dan penyuluhan hukum ini menjadi penting dilaksanakan agar perbedaan suku antar santri tetap dapat memupuk rasa gotong royong antar santri dan rasa persatuan bangsa. Penyuluhan dan edukasi ini diharapkan dapat memberikan informasi dan masukan yang berguna dan menambah khasanah ilmu pengetahuan dan wawasan kepada para santri mengenai penanaman karakter khususnya terkait dengan penanaman nilai persatuan dan tanggung jawab di dalam kehidupan sehari-hari dan dalam kehidupan bermasyarakat. Tujuannya adalah agar para santri dapat mengetahui mengenai faktor penyebab dari hal-hal yang merusak persatuan dan langkah apa yang harus ditempuh jika terjadi hal-hal yang dapat mengilangkan rasa persatuan dan kesatuan. Luaran yang akan dihasilkan dalam kegiatan ini adalah berupa laporan hasil pengabdian masyarakat disertai artikel P2M yang akan diterbitkan dalam jurnal Pengabdian Masyarakat Abdimas. Dalam artikel tersebut akan dicarikan langkah-langkah dalam pelaksanaan kegiatan tersebut, sehingga metode tersebut dapat diterapkan di tempat yang lain dengan kondisi permasalahan yang sama.
\end{abstract}

Kata kunci: Persatuan Indonesia 


\section{Pendahuluan}

Mitra dalam kegiatan Pengabdian Kepada Masyarakat ini adalah santri di Pesantren Rumah Quran Umar bin Khattab yang beralamat di Jl. Kp. Bojong Hilir No.12, Bojong, Kec. Kemamng, Bogor, Jawa Barat. Kegiatan pengabdian masyarakat ini dimulai dari bulan April 2020 sampai dengan bulan Agustus 2020 yang diawali dengan audiensi, rapat pembahasan tema, penandatangan kerjasama dan pelaksanaan edukasi/penyuluhan.

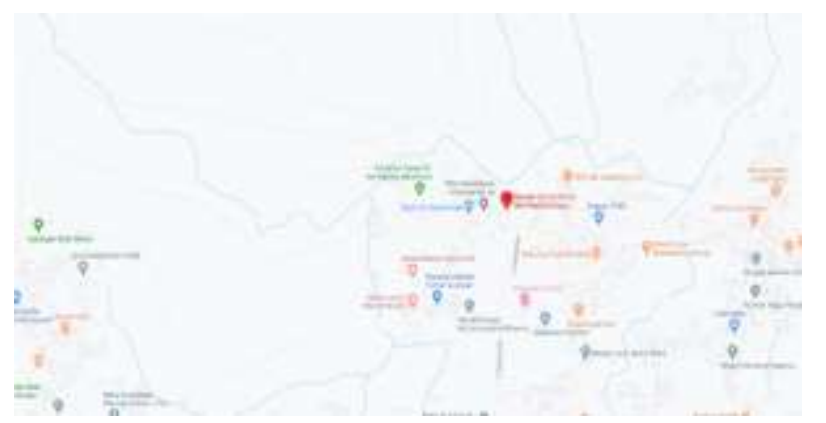

Foto Peta Lokasi (Pesantren Rumah Quran Umar Bin Khattab)

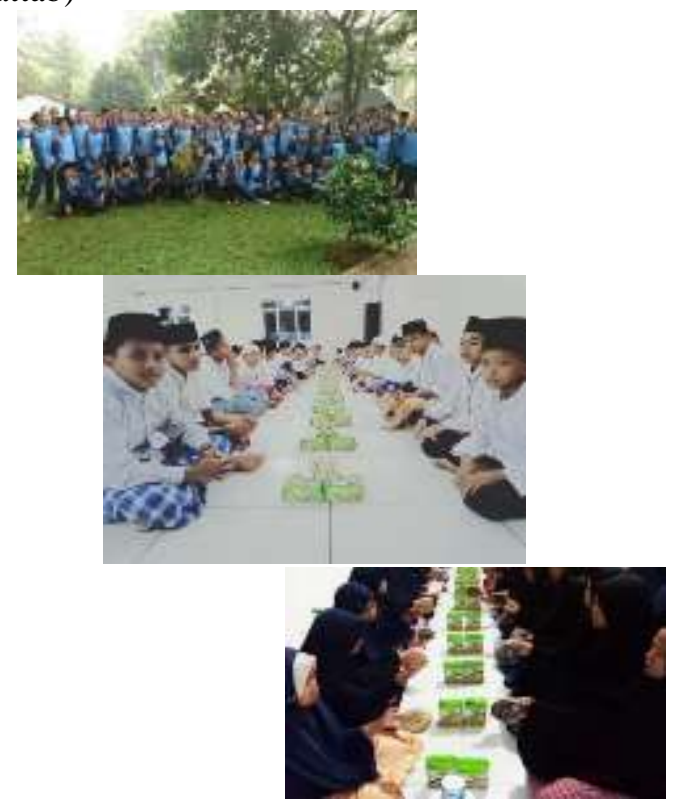

Ket: kegiatan audiensi dengan mitra terkait pembahasan masalah kebutuhan abdimas mitra

Pancasila sebagai dasar negara merupakan kesepakatan politik ketika negara Indonesia didirikan melalui sidang BPUPKI yang dihadiri dari berbagai utusan, baik dari utusan Islam maupun non-Islam. Pancasila merupakan pandangan hidup bangsa Indonesia. Pancasila artinya lima dasar atau lima asas yaitu nama dari dasar negara kita, Negara Republik Indonesia.
Sila ketiga dari Pancasila berbunyi "Persatuan Indonesia", negara Indonesia dikenal sebagai negara yang menjunjung tinggi nilainilai persatuan dan kesatuan bangsa dalam bingkai nasionalisme. Kekuatan nilai persatuan dan kesatuan dapat menjaga keutuhan bangsa dengan mewujudkan satu konsep identitas bersama bagi kelompok manusia. Bangsa yang benar-benar independen lahir dari kesadaran masyarakatnya akan pentingnya persatuan.

Representasi nilai-nilai persatuan pada masyarakat Indonesia adalah budaya gotong royong. Dahulu nilai gotong royong sangat terasa sekali, misalnya jika ada tetangga yang melaksanakan hajatan, ketika petani mau menanam padi di ladang atau memanen, upahnya hanya makan pagi dan siang atau makan kecil. Jadi, kalau ada diantara mereka menanam atau memanen, maka warga yang lainnya ikut gotong royong dan begitu sebaliknya sehingga terjadi semacam barter tenaga.

Sebagai pedoman hidup bangsa Indonesia, Pancasila berisi nilai-nilai luhur yang telah disepakati oleh para pendiri bangsa. Sila ketiga Pancasila yang berbunyi "Persatuan Indonesia" menyatakan tekad dan semangat bangsa Indonesia untuk bersatu meskipun Indonesia terdiri dari beragam suku dan bahasa.

Pancasila dapat difungsikan dalam setiap elemen kelembagaan, pendidikan, kebudayaan, dan organisasiorganisasi di Indonesia, misalnya di pesantren. Pesantren sebagai pendidikan tertua di Indonesia sangat berkembang pesat dan besar. Perkembangannya pun tidak hanya pada tekstual, namun lebih mengikuti perkembangan zaman, dengan tujuan mempersiapkan siswa atau santri lebih maju,bukan hanya ahli di bidang agama, namun tentang kepemerintahan juga digalakkan dengan diadakan Pendidikan-pendidikan di Pesantren.

Pesantren sendiri secara etimologis berasal dari kata dasar santri yang dengan awalan pe di depan dan akhiran "an" dibelakang berarti tempat tinggal santri. Pesantren menjadi tempat dari para santri untuk mendapatkan pengetahuan dan ajaran agama dari seorang ulama atau kiai. Dalam praktik pengajarannya, pondok pesantren memiliki konsep pengajaran agama Islam berdasarkan kepada Alquran dan 
hadis, juga kita-kitab Islam seperti Safinah, Taklimu Mutaallim, dan kitab lainnya yang merupakan karya dari tokoh Islam (Atabik, 2014).

Pesantren adalah institusi pendidikan yang berada di bawah pimpinan seorang atau beberapa kiai/ulama dan dibantu oleh seorang santri senior serta beberapa anggota keluarganya. Pesantren menjadi bagian penting bagi kiai sebab pesantren dapat difungsikan sebagai tempat untuk berdakwah, mengembangkan, dan melestarikan ajaranIslam.

Berdasarkan hasil survey yang sudah kami lakukan melalui audiensi dengan Yayasan Pesantren Rumah Quran Umar Bin khattab terkait dengan pengamalan Sila ke-3 Persatuan Indonesia tersebut adalah para santri berbeda suku yang tinggal di lingkungan Pesantren yang kerap kali menimbulkan masalah antar santri. Untuk itu, dengan diadakannya penyuluhan ini diharapkan dapat memupuk rasa persatuan antar santri.

Pengabdian masyarakat yang akan kami lakukan adalah dengan bentuk edukasi kepada masyarakat melalui penyuluhan hukum. Tujuan dari dilakukannya edukasi dan penyuluhan hukum ini adalah antara lain:

1. Para santri mampu menempatkan persatuan, kesatuan, serta kepentingan dan keselamatan bersama di atas kepentingan pribadi dan golongan.

2. Para santri mampu saling bekerjasama, bergotong royong dan memajukan pergaulan demi persatuan dan kesatuan bangsa.

3. Para santri mampu mengembangkan rasa cinta dan rasa kebanggaan berkebangsaan dan bertanah air Indonesia.

4. Para santri mampu mengembangkan persatuan Indonesia atas dasar Bhinneka Tunggal Ika.

Permasalahan yang terdapat pada para santri di Pesantren tersebut asalah:

1. Bagaimanakah cara menumbuhkan nilainilai tanggung jawab dan gotong royong terkait rasa persatuan antar santri di Pesantren Rumah Quran Umar bin Khattab?

2. Bagaimanakah cara mencerminan nilai-nilai persatuan yang muncul dari kehidupan sehari-hari para santri di Pesantren Rumah Quran Umar bin Khattab?
Kurangnya kesadaran para santri terkait rasa persatuan dan kesatuan bangsa, menimbulkan terjadinya kelompok-kelompok antarsuku di sana. Untuk itu, edukasi dan penyuluhan hukum ini menjadi penting dilaksanakan agar perbedaan suku antar santri tetap dapat memupuk rasa gotong royong antar santri dan rasa persatuan bangsa.

Untuk dapat menumbuhkan rasa persatuan dan kesatuan antar santri di Pesantren Rumah Quran Umar Bin Khattab Bogor, maka kami melakukan penyuluhan berupa edukasi kepada para santri tentang pentingnya gotong royong demi mewujudkan persatuan dan kesatuan para santri.

Penyuluhan dan edukasi ini diharapkan dapat memberikan informasi dan masukan yang berguna dan menambah khasanah ilmu pengetahuan dan wawasan kepada para santri mengenai penanaman karakter khususnya terkait dengan penanaman nilai persatuan dan tanggung jawab di dalam kehidupan sehari-hari dan dalam kehidupan bermasyarakat. Tujuannya adalah agar para santri dapat mengetahui mengenai faktor penyebab dari hal-hal yang merusak persatuan dan langkah apa yang harus ditempuh jika terjadi hal-hal yang dapat mengilangkan rasa persatuan dan kesatuan.

\section{Hasil dan Pembahasan}

\section{Cara menumbuhkan nilai-nilai tanggung} jawab dan gotong royong terkait rasa persatuan antar santri di Pesantren Rumah Quran Umar bin Khattab

Gotong royong dalam rangka menumbuhkan rasa tanggung jawab di pondok pesantren Rumah Quran Umar Bin Khattab Bogor sudah menjadi kebiasaan yang tidak bisa ditinggalkan karena berhubungan dengan kebersamaan, tenggang rasa baik dalam proses belajar mengajar dan khususnya dalam kebersihan lingkungan pesantren. Dengan terciptanya lingkungan yang bersih, maka suasana juga akan terasa nyaman.

Dalam rangka menumbuhkan atau meningkatkan karakter sosial santri, pondok pesantren Rumah Quran Umar Bin Khattab Bogor melakukan beberapa pembelajaran. Salah satu diantaranya adalah pembelajaran yang bersifat tidak formal yaitu kegiatan gotong royong membersihkan lingkungan atau sering 
kita dengar dengan istilah kerja bakti. Kegiatan tersebut dilaksanakan setiap hari, sehingga secara sadar ataupun tanpa disadari jiwa seorang santri telah terbubuhi oleh pendidikan karakter yang terkhususkan pada karakter sosial.

Dari hasil observasi yang tim lakukan bahwa, peran tradisi gotong royong dalam meningkatkan karakter sosial santri di pondok pesantren Rumah Quran Umar Bin Khattab Bogor dapat dirasakan setelah santri melakukan kegiatan tersebut. Ketika para santri terbiasa melakukan kegiatan tersebut dengan saling tolong menolong, maka sikap tolong menolong dan gotong royong akan terbiasa dilakukan oleh para santri.

Dengan menumbuhkan sikap dan perilaku gotong royong dan kebersamaan, maka karakter sosial para santri akan terbangun yaitu saling tolong menolong, kerjasama, toleransi, menghargai dan menghormati antar sesama serta memiliki rasa kepedulian atau solidaritas terhadap sesama. Dengan demikian para santri siap untuk terjun di tengah-tengah masyarakat dan dapat diterima dengan baik sesuai dengan harapan dan memiliki karakter sosial.

Hal tersebut dikarenakan pada hakikatnya manusia adalah sebagai makhluk sosial. Dengan bergotong royong dan saling tolong menolong maka faktor pendorong pelaksanaan kerjasama dan gotong royong antar manusia terpenuhi, seperti hakikatnya manusia sebagai makhluk social, rasa ikhlas dan tulus berpartisipasi dalam kebersamaan serta menjaga persatuan dan kesatuan, adanya kesadaran saling membantu serta mengutamakan kepentingan bersama atau umum, sehingga dapat meningkatkan atau memenuhi kesejahteraan dengan melakukan usaha penyesuaian serta integrasi atau penyatuan kepentingan sendiri dengan kepentingan Bersama.

\section{Cara mencerminan nilai-nilai persatuan yang muncul dari kehidupan sehari-hari para santri di Pesantren Rumah Quran Umar bin Khattab}

Berdasarkan dari hasil observasi tim di pondok pesantren Rumah Quran Umar Bin Khattab Bogor, bahwa hal- hal pendorong yang menjadi alat terlaksanakannya penerapan Nilainilai Pancasila khususnya nilai-nilai persatuan, diantaranya adalah melakukan pembelajaran baik secara formal maupun non formal yang merupakan faktor utama dalam membentuk kesadaran santri terhadap pentingnya khususnya nilai-nilai persatuan di lingkungan pesantren.

Dalam pendidikan formal terdapat pembelajaran langsung tentang Pancasila, fungsi, tujuan serta mamfaat penerapan Nilainilai Pancasila pada kehidupan. Sedangkan dalam pendidikan non formal diajarkan tentang Nilai- nilai keislaman, bagaiama manusia berakhlakul karimah pada tuhan dan makhluk ciptaanNya.

Faktor lain yang mendukung terbentuknya nilai-nilai persatuan pada kehidupan santri adalah program-program yang dibentuk oleh Pesantren meliputi kajian- kajian tentang kebangsaan, anti korupsi, penyuluhan maupun sosialisai yang dilakukan oleh para pendidik di lingkungan pesantren terkait perkembangan politik, ekonomi,

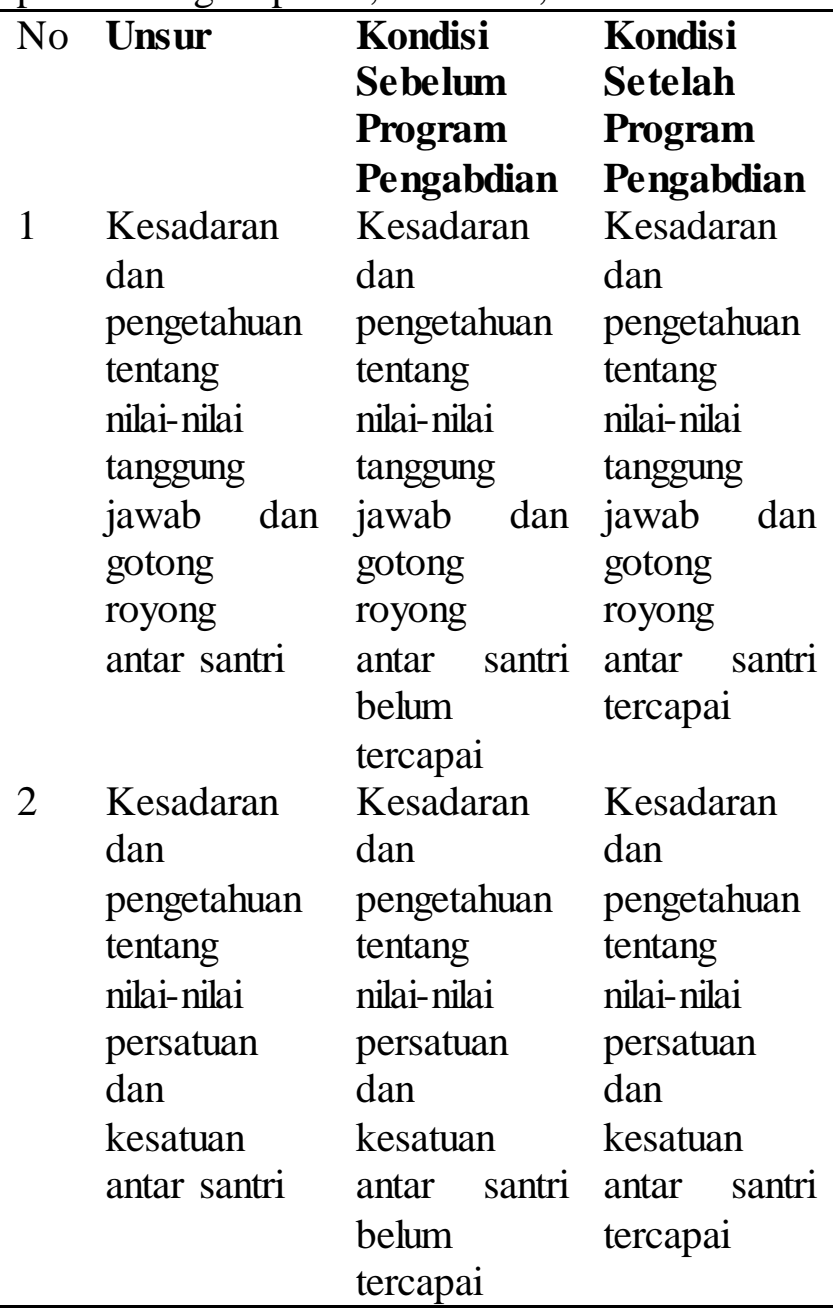


pendidikan dan kajian tentang pelanggaranpelanggaran yang terjadi di pemerintahan sebagai salah bentuk kesadaran berpancasila.

Pada setiap hari Nasional, pesantren Rumah Quran Umar Bin Khattab Bogor selalu mengadakan Upacara bendera merah putih. Misalnya, pada hari kemerdekaan Bangsa Indonesia yaitu pada Tanggal 17 Agustu ataupun pada hari santri nasional. Hal tersebut dibentuk agar para santri tertanam kesadaran cinta tanah air, rasa nasionalisme hingga menjadi santri yang Pancasilais yaitu mengamalkan Nilai- nilai Pancasila khususnya rasa persatuan dan kesatuan pada kehidupan sehari- harinya.

\section{Metode Pelaksanaan}

Kegiatan pengabdian kepada masyarakat ini berbentuk edukasi dan penyuluhan, dimana materi disesuaikan dengan kebutuhan dari mitra dan sesuai dengan permasalahan yang terjadi di lapangan. Adapun tahapan yang dilaksanakan terdiri dari:

a. Analisis kebutuhan, yaitu tim menemukan berbagai macam permasalahan terkait pengamalan sila ke-3 Pancasila Persatuan Indonesia yang terjadi di Pesantren Rumah Quran Umar Bin Khattab melalui informasi yang diterima pada saat survey dan audiensi.

b. Perencanaan penyuluhan, yaitu tim akan berbagi pengetahuan dengan memberikan edukasi dan penyuluhan dalam rangka menginformasikan mengenai bagaimana menumbuhkan nilai-nilai gotong royong dan tanggung jawab antar santri.

c. Evaluasi kegiatan, dimana antara tim dosen dan pembina Pesantren akan berkomunikasi secara berkelanjutan untuk melihat perubahan yang terjadi setelah dilakukannya penyuluhan ini dan akan ada perbaikan metode lagi jika ada hal yang kurang sesuai dengan harapan.

Harapan perubahan kondisi sebelum dan sesudah dilakukannya pengabdian masyarakat ini adalah:

\section{Kesimpulan}

Berdasarkan uraian diatas dan hasil survey di lapangan, dapat disimpulkan bahwa penanaman Nilai- nilai Pancasila di lingkungan pondok pesantren Rumah Quran Umar Bin Khattab Bogor dilakukan dengan membentuk kegiatan-kegiatan bago santri yaitu dengan saling gotong royong dan kerjasama, lalu dengan menanamkan nilai-nilai Pancasila dalam pendidikan baik itu secara formal ataupun non formal. Program ini juga merupakan sarana pendukung dalam menanamkan nilai- nilai Pancasila khususnya sila ke-3 Persatuan Indonesia pada kehidupan santri. Sedangkan bentuk-bentuk prilaku santri yang mencerminkan Nilai- nilai Pancasila khususnya sila ke-3 Persatuan Indonesia, yaitu seperti taat ibadah, taat aturan yang di buat oleh pesantren maupun oleh sekolah dengan tetap saling tolong menolong, saling menghormati, saling menjaga antara satu dengan yang lain, tidak melakukan sesuatu yang merugikan orang lain, saling menghargai perbedaan pendapat, perbedaan suku, etnis, budaya dan bahasa.

\section{Daftar Pustaka}

Arpannudin, I. (2016). Implementasi nilai 180okum180 ukhuwah islamiah di pondok pesantren. Humanika, 16(1), 121.

Atabik. (2014). Historisitas dan peran pondok pesantren Somalangu di Pesisir Selatan. Ibda' Jurnal Kebudayaan Islam A., 12(2), 185-197.

Baso, A. (2012). Akar 180okum180a180an kewarganegaraan di pesantren. Komnas HAM RI, XVII(4), 162-186.

Chairiyah. (2014). Revitalisasi nilai-nilai Pancasila sebagai 180okum180a180an karakter. Jurnal Pendidikan Ke-SD-an, 1(1), 54-62.

Kaelan. (2013). Negara kebangsaan Pancasila (kultural, historis, filosofis, yuridis, dan aktualisasinya). Yogyakarta: Pradikma.

Latif, Y. (2015). Negara paripurna: Historisitas, rasionalitas, dan aktualisasi Pancasila. Jakarta: PT Gramidia Pustaka Utama.

Rachmah, H. (2013). Nilai-nilai dalam 180okum180a180an karakter bangsa yang berdasarkan Pancasila dan UUD 
1945. E-Journal WIDYA Non-Eksakta, $1(1), 7-14$.

Surip, N., Syarbaini, S., \& Rahman, A. (2015). Pancasila dalam makna dan aktualisasi. Yogyakarta: CV. Andi Offset.

Tukiran, T., \& Udhie, H. (2014). Pemimpin berkarakter Pancasila. Bandung: Alfabeta.

Wahab, A. A., \& Sapriya. (2011). Teori dan landasan 181okuml81a181an kewarganegaraan. Bandung: Alfabeta. 